\title{
Flora da Usina São José, Igarassu, Pernambuco: Orchidaceae
}

\author{
Flora of Usina São José: Orchidaceae
}

\author{
Edlley Pessoa ${ }^{1,2}$ \& Marccus Alves ${ }^{1}$
}

\begin{abstract}
Resumo
Orchidaceae foi citada recentemente como a família mais representativa na Floresta Atlântica. Considerando essa representatividade, a fragmentação com perda de diversidade e a carência de informações para a área, este trabalho inventariou a flora orquidológica em remanescentes florestais na Usina São José (USJ), Pernambuco, Brasil. O estudo foi realizado em seis fragmentos na mata Norte Pernambucana, localizados no município de Igarassu. Foram realizadas expedições mensais de dezembro de 2008 a março de 2010. As amostras foram depositadas no herbário UFP. Orchidaceae está representada na área por 27 espécies e 19 gêneros, cujos mais representativos foram Epidendrum (4 spp.) e Scaphyglottis (3 spp.). Incrementa-se 20 spp. àquelas citadas para a USJ em lista anterior. Três espécies foram citadas pela primeira vez para a Floresta Atlântica, sendo uma um novo registro para flora nordestina. Cattleya granulosa Lindl. e Zygostates bradei (Schltr.) Garay estão incluídas em listas de espécies ameaçadas de extinção na categoria de vulneráveis. O fragmento Piedade merece destaque por apresentar 26 spp., sendo este uma RPPN. Os dados reforçam a importância da área para conservação da biodiversidade no estado.
\end{abstract}

Palavras-chave: checklist, monocotiledôneas, orquídeas, taxonomia, Floresta Atlântica.

\begin{abstract}
Orchidaceae was recently pointed as the most representative family in Atlantic forest. Based on the lack of data and the fragmentation with lost of diversity, this paper provides a checklist of the orchids in some fragments of Atlantic Rainforest in Usina São José (USJ), Pernambuco, Brazil. The study area includes six forest fragments in Igarassu, Pernambuco. Fieldwork was carried out from December/2008 to March/2010. The vouchers were deposited at UFP herbarium. Orchidaceae is represented by 27 species and 19 genera which Epidendrum L. (4 spp.) and Scaphyglottis Poepp. \& Endl.(3 spp.) were the richest in number of species. This work increases $20 \mathrm{spp}$. to that recorded for USJ in previous checklist. Three species are recorded here for the first time for the Atlantic rainflorest, and one is a new record to Northeastern Brazil. Cattleya granulosa Lindl. and Zygostates bradei (Schltr.) Garay are considered threatened. The Piedade remain is noteworthy for having 26 spp., which is a RPPN. The data shows the importance of the area to conservation of the biodiversity in the State.
\end{abstract}

Key words: checklist, monocots, orchids, taxonomy, Atlantic RainForest.

\section{Introdução}

A Floresta Atlântica é uma das zonas biogeográficas mais ricas em número de espécies e endemismos do mundo (Mittermeier et al. 1999) e considerada um hotspot de diversidade com alta prioridade para conservação (Myers et al. 2000). Abrange a costa litorânea brasileira desde o Rio Grande do Norte até o Rio Grande do Sul (Peixoto et al. 2002), alcançando a Argentina e o Paraguai na sua porção meridional (Conservation International et al. 2000). Dados atuais indicam que restam $11 \%$ do seu território original (Ribeiro et al. 2009). No Nordeste do Brasil, a situação é ainda mais crítica com a pressão da monocultura açucareira e a expansão dos centros urbanos, restando na região apenas pequenos fragmentos em topos de morros e encostas.

Orchidaceae está distribuída por todo o mundo e tem como centro de diversidade os

\footnotetext{
${ }^{1}$ Universidade Federal de Pernambuco, Depto. Botânica, Lab. Morfo-Taxonomia Vegetal, CCB, Av. Prof. Moraes Rêgo s/n, 50670-901, Recife, PE, Brasil.

${ }^{2}$ Autor para correspondência: edlley_max@hotmail.com
} 
trópicos (Ramussen 1985), sendo considerada a maior família de Angiospermas, com cerca de 20.000 espécies (Christenson 2004). O leste do Brasil é considerado como a segunda região mais rica em espécies da família no mundo (Pridgeon 1995). Stehmann et al. (2009) citaram Orchidaceae como a família mais diversa na Floresta Atlântica, com cerca de 1.300 espécies e 180 gêneros, correspondendo a $8 \%$ do total de táxons registrados para o bioma, além do alto número de endemismos.

No Brasil existem aproximadamente 2.420 espécies (Barros et al. 2012) e para a região Nordeste são citadas, por Barros \& Félix (2006), cerca de 550 spp. em 115 gêneros. Para o Estado de Pernambuco, Félix \& Carvalho (2002) listaram aproximadamente $250 \mathrm{spp}$. em 78 gêneros, comprovando a elevada diversidade da flora orquidológica estadual.

Os estudos com orquídeas são escassos para Floresta Atlântica costeira nordestina. Para a região, as informações estão concentradas nas formações interioranas como a Chapada Diamantina-BA(Toscano-de-Brito 1995; Toscanode-Brito \& Cribb 2005; Azevedo \& Van-den-Berg 2007) e os Brejos de Altitude (Lima-Verde 2003; Almeida et al. 2007).

Considerando a riqueza de Orchidaceae, sendo algumas bioindicadoras de conservação, o estado avançado de fragmentação e a perda de diversidade na região, aliado a carência de informações disponíveis para porção setentrional da Floresta Atlântica Nordestina, o presente trabalho busca inventariar a flora orquidológica em remanescentes do bioma no Estado de Pernambuco.

\section{Materiais e Métodos}

O presente estudo foi realizado na Usina São José $\left(07^{\circ} 50^{\prime} \mathrm{S}, 35^{\circ} 00^{\prime} \mathrm{W}\right)$, uma área de Floresta Atlântica ao norte do Estado de Pernambuco, localizada no município de Igarassu (Araújo \& Alves 2010). A Usina de São José (USJ) possui aproximadamente 110 fragmentos dos quais foram selecionados seis para o desenvolvimento deste estudo: Chave (101 ha), Macacos (357ha), Pezinho (29ha), Piedade (306ha), Santa Helena (12ha) e Zambana (388ha) (Trindade et al. 2008). O clima é do tipo As' (sensu Köppen), quente e úmido, com precipitação média anual de $1.689 \mathrm{~mm}$ e temperatura média de $24,9^{\circ} \mathrm{C}$ (dados da USJosé, período 1998 a 2003) e o relevo é de terras baixas, constituído por tabuleiros recortados por vales estreitos (CPRH 2003).
Foram realizadas expedições mensais de dezembro de 2008 a março de 2010, para observação e coleta de material. Os fragmentos visitados foram percorridos aleatoriamente visando a maior área de abrangência possível, totalizando aproximadamente 240 horas de esforço amostral. As amostras foram herborizadas segundo Mori et al. (1989), depositadas no herbário UFP, sendo as duplicatas enviadas para os herbários EAN, HST, IPA, JPB, MAC e PEUFR (siglas de acordo com Thiers 2010).

As identificações foram efetuadas com auxílio de literatura especializada (Hoehne 1949; Pabst \& Dungs 1975, 1977; Romero-González 2003; Toscano-de-Brito \& Cribb 2005), além de consultas às coleções de herbários (UFP, PEUFR, INPA, IPA e JPB). As informações ecológicas foram obtidas através de observações de campo e dados das etiquetas das exsicatas examinadas. A terminologia morfológica segue Harris \& Harris (2001) e Gonçalves \& Lorenzi (2007). Para os habitats (borda, declive, sítio ripário, tabuleiro e terraço) de Floresta Atlântica adotou-se Silva et al. (2008).

Este estudo é parte da série de publicações taxonômicas sobre os principais grupos de Angiospermas que ocorrem em fragmentos da Usina São José (Alves-Araújo \& Alves 2010; Melo et al. 2010; Pontes et al. 2010; Amorim \& Alves 2011; Buril \& Alves 2011).

\section{Resultados e Discussão}

Orchidaceae está representada na área por 27 espécies distribuídas em 19 gêneros, cujos mais representativos foram Epidendrum L. (4 spp.) e Scaphyglottis Poepp. \& Endl. (3 spp.). Incrementa-se 20 espécies àquelas citadas para a USJ na lista de Alves-Araújo (2008) que apresenta apenas sete.

Campylocentrum pachyrrhizum (Rchb. f.) Rolfe, Dichaea panamensis Lindl e Scaphyglottis sickii Pabst são aqui citadas pela primeira vez para a Floresta Atlântica. Campylocentrum pachyrrhizum, conhecido até então para a América do Norte, Central e norte da América do Sul (RomeroGonzález 2003), incluindo o Brasil, nos estados do AM e MT (Barros et al. 2012), é um novo registro para flora nordestina. Aspidogyne fissirostris (Brade \& Pabst) Campacci, conhecida apenas para os estados da Bahia e Espírito Santo (Barros et al. 2012), é um novo registro para Pernambuco. Cattleya granulosa Lindl. e Zygostates bradei 
(Schltr.) Garay estão incluídas nas listas de espécies ameaçadas de extinção do Ministério do Meio Ambiente (MMA 2008) e Fundação Biodiversitas (2008), respectivamente.

Os dados reforçam a importância da área para conservação da biodiversidade do bioma no Estado. Das áreas estudadas, o fragmento Piedade merece destaque por mostrar-se o mais rico em espécies de orquídeas, com 26 spp., sendo este uma RPPN, e os demais remanescentes encontram-se desprotegidos. Sugere-se a legalização destes para fins de conservação assim como a implantação de corredores ecológicos fundamentais a interligação dos mesmos.

\section{Chave de identificação para espécies de Orchidaceae da Usina São José}

1. Plantas áfilas; raízes achatadas dorso-ventralmente. 2.2 Campylocentrum pachyrrhizum

1'. Plantas folhosas; raízes cilíndricas.

2. Ervas terrícolas.

3. Flores calcaradas.

4. Pseudobulbos unifoliados; calcar escrotiforme... 11.1 Oeceoclades maculata

4'. Colmos multifoliados; calcar tubular.

5. Folhas lanceoladas; labelo ovado.... 1.1 Aspidogyne fissirostris

5'. Folhas elípticas a ovadas; labelo obovado 1.2 Aspidogyne foliosa

3'. Flores não calcaradas.

6. Flores não ressupinadas, labelo cuculado 13.1 Prescottia stachyodes

6'. Flores ressupinadas, labelo ligulado 16.1 Sarcoglottis grandiflora

2'. Ervas epífitas ou hemi-epífitas.

7. Inflorescência lateral.

8. Folhas membranáceas, inflorescências unifloras

5.1 Dichaea panamensis

8'. Folhas membranáceo-coriáceas, coriáceas ou crassas; inflorescências multifloras.

9. Pseudobulbos homoblásticos, ou colmos; folhas ao longo do caule

10. Flores não ressupinadas, labelo saquiforme..... 3.1 Catasetum macrocarpum

10'. Flores ressupinadas, labelo não saquiforme.

11. Epífitas; folhas coriáceas; flores calcaradas

2.1 Campylocentrum micranthum

11'. Hemiepífitas; folhas crassas; flores não calcaradas.

12. Folhas oblongas; flores amarelas.

12'. Folhas estreito-elípticas; flores alvo-esverdeadas

18.2 Vanilla planifolia

18.1 Vanilla bahiana

9'. Pseudobulbos heteroblásticos; folhas apenas no ápice e base do caule.

13. Pseudobulbos $\leq 2 \mathrm{~cm}$ de alt.

14. Folhas oblongas à oblongo-elípticas, ápice obtuso a arredondado 10.1 Notylia cf. barkeri

14'. Folhas estreito-elípticas, ápice agudo 19.1 Zygostates bradei

13'. Pseudobulbos $>2 \mathrm{~cm}$ de alt.

15. Sépalas laterais completamente conadas .... 15.1 Rodriguezia bahiensis 15'. Sépalas laterais parcialmente conadas. 8.1 Gomesa barbata

7'. Inflorescência terminal.

16. Pseudobulbos sobrepostos

17. Folhas cilíndricas; labelo de ápice emarginado ..... 17.1 Scaphyglottis emarginata

17’. Folhas planas; labelo de ápice agudo ou cuspidado

18. Folhas 2; ovário pedicelado $\leq 0,6 \mathrm{~cm}$ compr. .........17.1. Scaphyglottis sickii

18 '. Folha 1; ovário pedicelado $>0,6 \mathrm{~cm}$ compr. .. 17.2. Scaphyglottis fusiformis

16'. Pseudobulbos não sobrepostos.

19. Pseudobulbos ovóides $\leq 2,0 \mathrm{~cm}$ de compr. 12.1Polystachya concreta

19'. Colmos ou pseudobulbos nunca ovóides $>2,0 \mathrm{~cm}$ de compr.

20. Pseudobulbos uni a trifoliados. 
21. Pseudobulbos cilíndricos, folhas 2-3; flores ressupinadas 4.1 Cattleya granulosa

21'. Pseudobulbos claviformes, folhas 1-2; flores não ressupinadas 14.1 Prosthechea fragrans 20'. Colmos ou pseudobulbos multifoliados.

22. Caule ramificado 7.4 Epidendrum strobiliferum

22'. Caule nunca ramificado.

23. Coluna parcialmente adnata ao labelo.

24. Colmo $\leq 7 \mathrm{~cm}$ compr.; folhas sub-cilíndricas, canaliculadas

9.1 Jacquiniella globosa

24'. Pseudobulbo $>7 \mathrm{~cm}$ compr.; folhas lineares, planas 6.1 Dimerandra emarginata 23'. Coluna inteiramente adnata ao labelo.

25. Pedúnculo da inflorescência $>2,5 \mathrm{~cm}$ compr.; flores vermelhas 7.1 Epidendrum macrocarpum

25 '. Pedúnculo da inflorescência $\leq 2,5 \mathrm{~cm}$ compr.; flores verdes ou alvas

26. Folhas oblongo-elípticas; flores verdes, labelo inteiro ... 7.3 Epidendrum rigidum 26'. Folhas linerares; flores alvas, labelo trilobado 7.2 Epidendrum nocturnum

\section{Aspidogyne Garay}

1.1 Aspidogyne fissirostris (Brade \& Pabst) Campacci, Bol. CAOB 58: 50.2005. Fig. 1a, 3a

Terrestre, simpodial. Raízes cilíndricas. Colmo 6-13 × 0,1-0,15 cm, cilíndrico. Folhas 3-6, ao longo do caule, $2,5-6 \times 0,5-1 \mathrm{~cm}$, lanceoladas, ápice agudo, membranáceas. Inflorescência terminal, racemo, multiflora, laxa; pedúnculo 2,5-7 cm compr.; raque 2-6 cm compr.; brácteas florais $0,5-0,6 \mathrm{~cm}$ compr. Flores ressupinadas, alvas; sépala dorsal $0,3-0,4 \times 0,1 \mathrm{~cm}$, linearoblanceolada, ápice agudo; sépalas laterais $0,3-0,4$ $\times 0,1 \mathrm{~cm}$, linear-oblanceoladas, ápice agudo; pétalas, $0,3-0,4 \times 0,1 \mathrm{~cm}$, oblanceoladas, ápice agudo; labelo, $0,3-0,4 \times 0,15-0,2 \mathrm{~cm}$, ovado, ápice agudo; calcar, $0,4 \mathrm{~cm}$ compr., tubular; coluna $0,25-0,3 \mathrm{~cm}$ compr.; ovário pedicelado $0,5-0,6 \mathrm{~cm}$ compr.. Fruto $0,6-0,7 \times 0,15-0,2 \mathrm{~cm}$, falciforme. Material examinado: Mata de Piedade, 15.XII.2009, fl., J.A.N. Souza 580 (IPA, UFP); 02.III.2010, fl. e fr., E. Pessoa \& J.D. Garcia 260 (HST, UFP).

Endêmica do Brasil, até o presente trabalho conhecida apenas para os estados da Bahia e Espírito Santo (Barros et al. 2012), sendo um novo registro para Pernambuco. Rara em sítios ripários, ocorrendo nas bordas de pequenos córregos. Apenas uma população com cerca de uma dezena de indivíduos foi observada. Pode ser diferenciada da outra espécie do gênero na área pelo menor porte e formato das folhas (lanceoladas vs. elípticas a ovadas).

1.2 Aspidogyne foliosa (Poepp. \& Endl.) Garay, Bradea 2: 201. 1977.

Fig. $1 b, 3 b$

Terrestre, simpodial. Raízes cilíndricas. Colmo 16-22 × 0,2-0,3 cm, cilíndrico. Folhas
7-13, ao longo do caule, 4-11 × 1,6-4 cm, elípticas a ovadas, ápice agudo a acuminado, membranáceas. Inflorescência terminal, racemo, multiflora, congesta; pedúnculo 1,5-3 cm compr.; raque 6-15 $\mathrm{cm}$ compr.; brácteas florais $0,5-0,7 \mathrm{~cm}$ compr. Flores ressupinadas, alvas; sépala dorsal 0,35-0,4 × $0,1-0,15 \mathrm{~cm}$, elíptica, ápice agudo; sépalas laterais 0,4-0,6 × 0,1-0,2 cm, obovadas, ápice agudo; pétalas $0,4 \times 0,1 \mathrm{~cm}$, oblanceoladas, ápice agudo; labelo $0,5-0,6 \times 0,2-0,25 \mathrm{~cm}$, obovado, constricto no terço distal, ápice arredondado; calcar $0,2-0,3$ $\mathrm{cm}$ compr., tubular; coluna $0,2-0,3 \mathrm{~cm}$ compr.; ovário pedicelado $1-1,2 \mathrm{~cm}$ compr. Fruto $0,7-0,8$ $\times 0,15-0,2 \mathrm{~cm}$, falciforme.

Material examinado selecionado: Mata de Piedade, 21.XI.2009, fl. e fr., E. Pessoa \& J.A.N. Souza 105 (EAN, HST, IPA, JPB, MAC, UFP); 29.X.2009, fl. e fr., J.D. Garcia 1253 (IPA, UFP).

Amplamente distribuída na América do Sul (Ormerod 2009). Ocasional em tabuleiros. Ciclo de vida rápido, com os indivíduos geralmente ocorrendo próximos entre si e apresentando floração sincrônica. Pode ser diferenciada da outra espécie do gênero na área pelo maior porte, com caules de até $22 \mathrm{~cm}$ compr.

\section{Campylocentrum Benth}

2.1 Campylocentrum micranthum (Lindl.) Rolfe, Orch. Rev. 11: 245. $1903 . \quad$ Fig. 1c

Epífita, monopodial. Raízes cilíndricas. Colmo 3,8-33,5 × 0,2-0,4 cm, cilíndrico. Folhas $4-17$, ao longo do caule, $3,2-7 \times 0,7-1,6 \mathrm{~cm}$, elípticas a estreito-oblongas, ápice emarginado a assimétrico, coriáceas. Inflorescência lateral, racemo, multiflora, sub-congesta; pedúnculo $0,1-$ $0,2 \mathrm{~cm}$ compr.; raque $0,5-1,8 \mathrm{~cm}$ compr.; brácteas 

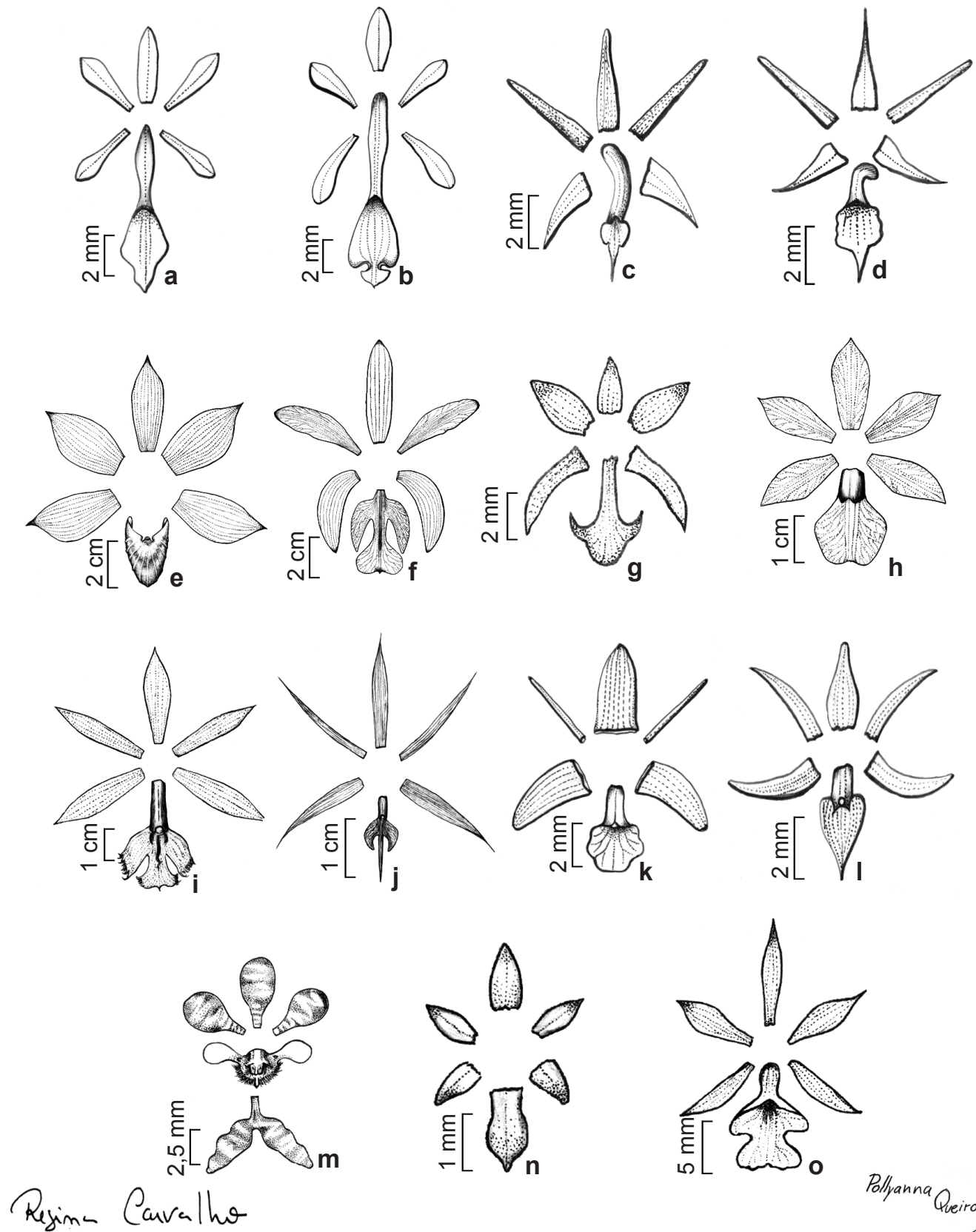

$$
\text { Regine Carrallo }
$$

Figura 1 - Diagramas Florais. a. Aspidogyne fissirostris; b. Aspidogyne foliosa Garay; c. Campylocentrum micranthum Rolfe; d. Campylocentrum pachyrrhizum; e. Catasetum macrocarpum; f. Cattleya granulosa; g. Dichaea panamensis; h. Dimerandra emarginata; i. Epidendrum macrocarpum; j. Epidendrum nocturnum; k. Epidendrum rigidum; 1. Epidendrum strobiliferum f.; m. Gomesa barbata; n. Jacquiniella globosa; o. Oeceoclades maculata.

Figure 1 - Floral diagrams. a. Aspidogyne fissirostris; b. Aspidogyne foliosa; c. Campylocentrum micranthum; d. Campylocentrum pachyrrhizum; e. Catasetum macrocarpum; f. Cattleya granulosa; g. Dichaea panamensis; h. Dimerandra emarginata; i. Epidendrum macrocarpum; j. Epidendrum nocturnum; k. Epidendrum rigidum; 1 . Epidendrum strobiliferum f.; m. Gomesa barbata; n. Jacquiniella globosa; o. Oeceoclades maculata. 
florais $0,1 \mathrm{~cm}$ compr. Flores ressupinadas, alvas; sépala dorsal 0,25-0,3 ×0,1 cm, linear-lanceolada, ápice agudo; sépalas laterais $0,3 \times 0,07-0,1 \mathrm{~cm}$, linear-lanceoladas, ápice agudo; pétalas 0,25-0,3 $\times$ 0,05-0,07 cm, linear-elípticas, ápice agudo; labelo $0,2-0,3 \times 0,15 \mathrm{~cm}$, ligeiramente trilobado, ápice agudo; calcar 0,25-0,3 cm compr., encurvado; coluna $0,1 \mathrm{~cm}$ compr.; ovário pedicelado $0,4-0,5$ cm compr. Fruto 0,7-1 ×0,2-0,3 cm, elipsóide.

Material examinado selecionado: Mata de Piedade, 16.XII.2009, fl. e fr., E. Pessoa \& J.A.N. Souza 212 (HST, IPA, JPB, MAC, UFP ); 18.XII.2009, fl. e fr., J.A.N. Souza \& E. Pessoa 581 (UFP); 1.III.2010, fl. e fr., E. Pessoa \& J.D. Garcia 257 (UFP).

Ocorre do México ao sul do Brasil (RomeroGonzález 2003). Ocasional em sítios ripários e tabuleiros. Vive preferencialmente no sub-bosque. É facilmente diferenciada das demais espécies da área pelas inflorescências multifloras laterais curtas (até $2 \mathrm{~cm}$ ).

\subsection{Campylocentrum pachyrrhizum (Rchb. f.)} Rolfe, Orch. Rev. 11: 246. $1903 . \quad$ Fig. 1d, 3c

Epífita, monopodial. Raízes achatadas dorso-ventralmente. Colmo vestigial. Áfila. Inflorescência lateral, racemo, multiflora, laxa; pedúnculo 0,1-0,2 cm compr.; raque $1,5-2 \mathrm{~cm}$ compr.; brácteas florais $0,2 \mathrm{~cm}$ compr. Flores ressupinadas, alvo-esverdeadas; sépala dorsal 0,35 $\times 0,07 \mathrm{~cm}$, lanceolada, ápice agudo; sépalas laterais $0,35 \times 0,1 \mathrm{~cm}$, lanceoladas, ápice agudo; pétalas $0,35 \times 0,05 \mathrm{~cm}$, lineares, ápice agudo; labelo 0,37 $\times 0,17 \mathrm{~cm}$, trilobado, ápice agudo; coluna $4 \mathrm{~cm}$ compr.; calcar 0,22 cm compr., claviforme, ovário pedicelado 0,27-0,3 cm compr. Fruto, 0,7-1,2 $\times$ 0,2-0,3 cm, elipsóide.

Material examinado: Mata de Piedade, 16.XII.2009, fl. e fr., E. Pessoa \& J.A.N. Souza 209 (UFP); 4.II.2010, fr. J.D. Garcia 1430 (IPA).

Conhecida até então desde o estado americano da Flórida ao norte do Brasil (Romero-González 2003), tendo aqui sua distribuição ampliada para o nordeste brasileiro. Rara em tabuleiros e com poucos indivíduos observados em campo. Esta espécie é a única áfila na área, sendo assim facilmente identificada.

\section{Catasetum Rich. ex Kunth}

3.1 Catasetum macrocarpum Rich. ex Kunth, Syn. P1. 1: 331. 1822.

Fig. 1e, 3d

Epífita, simpodial. Raízes cilíndricas. Pseudobulbo 4,5-12 × 1-3 cm, homoblástico, fusiforme. Folhas 7-9, ao longo do caule, 6,5-40
× 2,5-6 cm, elípticas, ápice agudo, membranáceocoriáceas. Inflorescência lateral, racemo, multiflora, laxa; pedúnculo $12-33 \mathrm{~cm}$ compr.; raque 2,5-12 cm compr.; brácteas florais $1-1,5 \mathrm{~cm}$ compr. Flores não ressupinadas, amarelo-esverdeadas; sépala dorsal 4,5-5 × 1,2-1.4 cm, oblonga, ápice agudo; sépalas laterais 4,5-5 × 1,5-2,5 cm, largoelípticas, ápice agudo; pétalas 4,5-5 × 2-2,5 cm, elípticas, ápice agudo; labelo 2,2-3,2 × 2-2,5 cm, saquiforme, ápice rostrado; coluna $4 \mathrm{~cm}$ compr.; ovário pedicelado $1,2-1,5 \mathrm{~cm}$ compr. Fruto 10-12 $\times 3-4 \mathrm{~cm}$, fusiforme.

Material examinado: Mata de Piedade, 25.XI.2009, fl., E. Pessoa \& J.A.N. Souza 192 (UFP); 16.XII.2009, fr., E. Pessoa \& J.A.N. Souza 213 (UFP).

Ocorre do norte da América do sul ao sudeste do Brasil (Pabst \& Dungs 1975). Comum em tabuleiros e terraços, com indivíduos habitando áreas próximas a grandes espelhos d'água e expostos ao sol. As flores vistosas associadas ao labelo saquiforme a distingue das demais espécies da área.

\section{Cattleya Lindl.}

4.1 Cattleya granulosa Lindl., Edwards's Bot. Reg. 28: 1. 1842.

Fig. $1 \mathrm{f}$

Epífita, simpodial. Raízes cilíndricas. Pseudobulbo 14-51 × 0,4-1,3 cm, homoblástico, cilíndrico. Folhas 2-3, apicais, 9,5-20 × 4-8 cm, oblongas, ápice arredondado, crassas. Inflorescência terminal, racemo, pauciflora, laxa; pedúnculo 4-6,5 cm compr.; raque 1,2-4,5 cm compr.; brácteas florais $0,5 \mathrm{~cm}$ compr. Flores ressupinadas, marrom-róseas; sépala dorsal $7 \times 1,2 \mathrm{~cm}$, elíptica, ápice agudo; sépalas laterais $5 \times 1,1 \mathrm{~cm}$, falcadas, ápice agudo; pétalas $6 \times 2 \mathrm{~cm}$, espatuladas a oblanceoladas, ápice agudo; labelo 4,5 × 3,2 cm, trilobado, ápice retuso; coluna $3 \mathrm{~cm}$ compr., parcialmente fundida ao labelo; ovário pedicelado 3,2-3,5 cm compr. Fruto não observado.

Material examinado: Mata de Piedade, 4.II.2010, J.D. García 1432 (UFP); 1.III.2010, E. Pessoa \& J.D. García 259 (IPA).

Material adicional: BRASIL, Pernambuco: Jaqueira, 1983, fl., M.S. Silva s/n (UFP 6986).

Espécie endêmica do litoral brasileiro. Incluída nas listas de espécies ameaçadas de extinção do MMA (2008) e Fundação Biodiversitas (2008). Rara em tabuleiros, os poucos indivíduos observados são oriundos do dossel, o que pode estar relacionado ao extrativismo excessivo. Suas flores estão entre as mais vistosas das espécies da área, tendo o labelo róseo e profundamente trilobado que a diferencia das demais. 


\section{Dichaea Lindl.}

5.1 Dichaea panamensis Lindl., Gen. et Spec. Orch. Pl.: 209. 1833.

Fig. $1 \mathrm{~g}, 3 \mathrm{e}$

Epífita, monopodial. Raízes cilíndricas. Colmo 4,2-12 × 0,2 cm, cilíndrico. Folhas 8-35, ao longo do caule, 1,3-4,2 $\times 0,2-0,4 \mathrm{~cm}$, lineares, ápice agudo, membranáceas. Inflorescência lateral, uniflora; pedúnculo 1,5-1,7 cm compr.; brácteas florais 0,1 $\mathrm{cm}$ compr. Flores ressupinadas, alvas; sépala dorsal 0,3-0,5 × 0,2 cm, lanceolada, ápice agudo; sépalas laterais $0,5-0,6 \times 0,15 \mathrm{~cm}$, sub-falcadas, ápice agudo; pétalas $0,5 \times 0,2 \mathrm{~cm}$, elípticas, ápice agudo; labelo 0,6 $\times 0,4-0,5 \mathrm{~cm}$, trilobado, ápice arredondado; coluna $0,3-0,4 \mathrm{~cm}$ compr.; ovário pedicelado $0,15-0,2 \mathrm{~cm}$ compr. Fruto $0,7-1 \times 0,2-0,4 \mathrm{~cm}$, obovóide.

Material examinado selecionado: Mata de Piedade, 23.XI.2009, fl. e fr., E. Pessoa \& J.A.N. Souza 114 (EAN, HST, JPB, MAC, PEUFR, UFP); 16.XII.2009, fl., E. Pessoa \& J.A.N. Souza 198 (IPA, UFP).

Ocorre do México ao nordeste do Brasil (Romero-González 2003). Comum em tabuleiros, terraços e sítios ripários. Epífita de sombra, vive preferencialmente em sub-bosque úmido. As inflorescências unifloras laterais a diferencia das demais espécies.

\section{Dimerandra Schltr.}

6.1 Dimerandra emarginata (G. Mey.) Hoehne, Bol. Agric. (São Paulo) 34: 618. $1934 . \quad$ Fig. 1h

Epífita, simpodial. Raízes cilíndricas. Pseudobulbo 5-26 × 0,2-0,5 cm, homoblástico, cilíndrico. Folhas 4-14, ao longo do caule, 2-8 $\times$ 0,3-0,7 cm, lineares, ápice emarginado, coriáceas. Inflorescência terminal, racemo, pauciflora, laxa; pedúnculo $0,2-0,6 \mathrm{~cm}$ compr.; raque $0,2-0,4 \mathrm{~cm}$ compr.; brácteas florais $0,3 \mathrm{~cm}$ compr. Flores ressupinadas, róseas; sépala dorsal 1,4-1,6 $\times 0,4$ $0,7 \mathrm{~cm}$, elíptico-lanceolada, ápice agudo; sépalas laterais $1,5-1,7 \times 0,3-0,7 \mathrm{~cm}$, elíptico-lanceoladas, ápice agudo; pétalas 1,6-1,8 ×0,7-1 cm, elípticas a obovadas, ápice agudo; labelo 1,7-1,9 × 1-1,4 $\mathrm{cm}$, suborbicular, ápice emarginado; coluna $0,4-0,6$ $\mathrm{cm}$ compr., parcialmente adnata ao labelo; ovário pedicelado 1,3-1,5 cm compr. Fruto 3,3-4 × $0,5-0,8 \mathrm{~cm}$, fusiforme.

Material examinado selecionado: Mata de Piedade, 23.XI.2009, fl. e fr., E. Pessoa \& J.A.N. Souza 112 (UFP); 16.XII.2009, fl. e fr., E. Pessoa \& J.A.N. Souza 201 (IPA).

Ocorre do México ao sudeste do Brasil (Dressler 2003). Comum em áreas de tabuleiro, terraços e sítios ripários, podendo ocorrer nos mais diversos extratos da floresta, exposta ao sol ou em sombra. Apesar de semelhante ao gênero Epidendrum L., esta espécie não possui a coluna completamente adnada ao labelo.

\section{Epidedrum L.}

7.1 Epidendrum macrocarpum Rich., Actes Soc. Hist. Nat. Paris 1(1): 112. 1792. Fig. 1i

Epífita, simpodial. Raízes cilíndricas. Colmo $15-36 \times 0,4-0,8 \mathrm{~cm}$, cilíndrico. Folhas $8-11$, ao longo do caule, $6,5-12 \times 1-2,8 \mathrm{~cm}$, oblongo-elípticas, ápice arredondado, coriáceas. Inflorescência terminal, corimbo, pauciflora, subcongesta; pedúnculo $6,3-17 \mathrm{~cm}$ compr.; raque 0,7-2,3 cm compr.; brácteas florais $0,3-0,9 \mathrm{~cm}$ compr. Flores ressupinadas, vermelhas; sépala dorsal 2,3-2,4 × 0,3-0,4 cm, elíptica, ápice agudo; sépalas laterais $2-2,3 \times 0,3-0,4 \mathrm{~cm}$, subfalcadas, ápice agudo; pétalas 2,2-2,3 × 0,2-0,4 $\mathrm{cm}$, elípticas, ápice agudo; labelo $2,3 \times 0,13 \mathrm{~cm}$, trilobado, ápice cuspidado; coluna, $1 \mathrm{~cm}$ compr., inteiramente adnata ao labelo; ovário pedicelado $3,8-4 \mathrm{~cm}$ compr. Fruto $8-8,5 \times 1,2-2,2 \mathrm{~cm}$, globoso-elípsóide.

Material examinado: Mata de Piedade, 21.XI.2009, fl., E. Pessoa \& J.A.N. Souza 104 (HST, IPA, MAC, UFP); 16.XII.2009, fl. e fr., E. Pessoa \& J.A.N. Souza 214 (UFP).

Ocorre no Norte e Nordeste do Brasil (Barros \& Félix 2006; Silva et al. 1995). Ocasional em tabuleiros. Encontrada principalmente no dossel, e na área pode ser distinguida das demais espécies do gênero pela inflorescência longo-pedunculada (até $17 \mathrm{~cm}$ compr.).

7.2 Epidendrum nocturnum Jacq., Enum. Syst. P1: 29. 1760.

Fig. $1 \mathrm{j}$

Epífita, simpodial. Raízes cilíndricas. Colmo $5,5-9,5 \times 0,1-0,2 \mathrm{~cm}$, cilíndrico. Folhas 4-6, ao longo do caule, 7,8-9,5 × 0,5-0,8 cm, lineares, ápice agudo, coriáceas. Inflorescência terminal, racemo, pauciflora, laxa; pedúnculo $0,6-0,9 \mathrm{~cm}$ compr.; raque $0,2-0,5 \mathrm{~cm}$ compr.; brácteas florais $0,2 \mathrm{~cm}$ compr. Flores ressupinadas, alvas; sépala dorsal 1,8 $\times 0,3 \mathrm{~cm}$, lanceolada, ápice acuminado; sépalas laterais $2 \times 0,2 \mathrm{~cm}$, lanceoladas, ápice acuminado; pétalas $1,8-1,9 \times 0,1 \mathrm{~cm}$, lineares, ápice acuminado; labelo $1,3 \times 0,6 \mathrm{~cm}$, trilobado, ápice agudo; coluna $0,8 \mathrm{~cm}$ compr., inteiramente adnata ao labelo; ovário pedicelado 1,3-1,5 cm compr. Fruto $3 \times 0,6 \mathrm{~cm}$, globoso-elipsóide.

Material examinado selecionado: Mata de Piedade, 16.XII.2009, fl. e fr., E. Pessoa \& J.A.N. Souza 211 (IPA, UFP). 
Ocorre desde o estado americano da Florida até o sul do Brasil (Romero-González 2003). Rara em tabuleiros. As flores aparentam ser cleistógamas. Diferencia-se das outras espécies do gênero na área por possuir raque muito curta (<1,0 cm compr.).

7.3 Epidendrum rigidum Jacq., Enum. Syst. Pl. 29. 1760.

Fig. $1 \mathrm{k}, 3 \mathrm{f}$

Epífita, simpodial. Raízes cilíndricas. Colmo 3,7-15 × 0,4-0,5 cm, cilíndrico. Folhas 5-10, ao longo do caule, $2,4-6 \times 0,8-1,4 \mathrm{~cm}$, oblongo-elípticas, ápice arredondado, coriáceas. Inflorescência terminal, racemo, pauciflora, laxa; pedúnculo $0,5-1,3 \mathrm{~cm}$ compr.; raque $4-8 \mathrm{~cm}$ compr.; brácteas florais $1-1,6 \mathrm{~cm}$ compr. Flores ressupinadas, verdes; sépala dorsal $0,5 \times 0,2 \mathrm{~cm}$, lanceolada, ápice agudo; sépalas laterais $0,5-0,6$ $\times 0,2-0,3 \mathrm{~cm}$, lanceoladas, ápice agudo; pétalas $0,4-0,5 \times 0,1 \mathrm{~cm}$, lineares, ápice agudo; labelo 0,5 $\times 0,3-0,35 \mathrm{~cm}$, suborbicular, ápice arredondado; coluna $0,25-0,3 \mathrm{~cm}$ compr., inteiramente adnata ao labelo; ovário pedicelado $0,8-0,9 \mathrm{~cm}$ compr. Fruto 1,5-2,5 × 0,3-1 cm, ovóide.

Material examinado selecionado: Mata dos Macacos, 15.VIII.2007, fl., A. Alves-Araújo et al. 520 (UFP); Mata de Piedade, 23.XI.2009, fl. e fr., E. Pessoa \& J.A.N. Souza 111 (IPA, UFP).

Distribui-se por toda America do Sul tropical (Romero-González 2003). Comum em tabuleiros, declives, terraços e sítios ripários e em diferentes extratos da floresta. $\mathrm{Na}$ área pode ser confundida com E. strobiliferum Rchb. f., porém se diferencia pelos caules secundários não ramificados.

7.4 Epidendrum strobiliferum Rchb. f., Ned. Kruidk. Arch. 4: 333. $1859 . \quad$ Fig. 11

Epífita, simpodial. Raízes cilíndricas. Colmo $9,5-14 \times 0,2-0,3 \mathrm{~cm}$, cilíndrico, ramificado. Folhas $15-29$, ao longo do caule, $2,2-3,8 \times 0,5-0,7 \mathrm{~cm}$, oblongo-laceoladas, ápice emarginado, coriáceas. Inflorescência terminal, racemo, pauciflora, laxa; pedúnculo $0,2-0,8 \mathrm{~cm}$ compr.; raque $1,2-2 \mathrm{~cm}$ compr.; brácteas florais $0,6-0,9 \mathrm{~cm}$ compr. Flores ressupinadas, verdes; sépala dorsal $0,35-0,4 \times$ $0,1 \mathrm{~cm}$, lanceolada, ápice agudo; sépalas laterais 0,3-0,4×0,1 cm, sub-falcadas, ápice agudo; pétalas $0,3-0,35 \times 0,05 \mathrm{~cm}$, lineares, ápice agudo; labelo $0,3-0,4 \times 0,2 \mathrm{~cm}$, cordiforme, ápice agudo; coluna $0,1-0,15 \mathrm{~cm}$ compr., inteiramente adnata ao labelo; ovário pedicelado $0,4-0,5 \mathrm{~cm}$ compr. Fruto $0,8 \times$ 0,3-0,4 cm, ovóide.
Material examinado: Mata de Piedade, 23.XI.2009, fl. e fr., E. Pessoa \& J.A.N. Souza 113 (UFP); 16.XII.2009, fr., E. Pessoa \& J.A.N. Souza 199 (UFP).

Espécie amplamente distribuída nos neotrópicos (Romero-González 2003). Rara em tabuleiros e associada a áreas úmidas. Pode ser confundida com E. rigidum porém diferencia-se pelos caules secundários ramificados.

\section{Gomesa}

8.1 Gomesa barbata (Lindl.) M. W. Chase \& N. H. Williams, Ann. Bot..104(3): 395. 2009.

Fig. $1 \mathrm{~m}$

Epífita, simpodial. Raízes cilíndricas. Pseudobulbo 2,5-4,5 × 1-2,4 cm, heteroblástico, ovóide, angulado. Folhas 2 basais, 1 apical, 5,5-18 $\times 0,9-2,2 \mathrm{~cm}$, oblongo-elípticas, ápice obtuso, coriáceas. Inflorescência lateral, racemo ou panícula, multiflora, laxa; pedúnculo $16-18,5 \mathrm{~cm}$ compr.; raque $2,5-15 \mathrm{~cm}$ compr.; brácteas florais 0,2-0,5 cm compr. Flores ressupinadas, marromamareladas; sépala dorsal $0,8-1 \times 0,38-0,41 \mathrm{~cm}$, estreito-ovada, ápice arredondado; sépalas laterais 0,9-1,3 × 0,3-0,5 cm, elípticas, ápice agudo, conadas no terço inferior; pétalas $0,7-1 \times 0,35-0,45$ $\mathrm{cm}$, estreito-obovadas, ápice arredondado; labelo 0,55-0,6 $\times 1,5 \mathrm{~cm}$, trilobado, ápice agudo; coluna 0,47-0,55 cm compr.; ovário pedicelado 1,6-1,9 $\mathrm{cm}$ compr. Fruto não observado.

Material examinado: Mata de Piedade, 16.XII.2009, fl., E. Pessoa \& J.A.N. Souza 206 (IPA, UFP); 1.III.2010, fl., E. Pessoa \& J.D. Garcia 256 (HST, UFP).

Material adicional: BRASIL, Pernambuco: Brejo da Madre de Deus, 12/XI/2003, fl., J. A. Siqueira-filho 1405 (UFP).

Conhecida para o Nordeste e Sudeste do Brasil (Pabst \& Dungs 1977). Ocasional em tabuleiros e ocorrência em dossel. Análises moleculares recentes demonstraram que Oncidium Sw. não é monofilético, tendo sido grande parte das espécies brasileiras do gênero transferidas para Gomesa (Chase et al. 2009). Pode ser facilmente diferenciada das demais espécies da área por possuir inflorescências multifloras com flores marrom-amareladas.

\section{Jacquiniella Schltr.}

9.1 Jacquiniella globosa (Jacq.) Schltr., Repert. Spec. Nov. Regni Veg., Beih. 7: 124. 1920.

Fig. 1n

Epífita, simpodial. Raízes cilíndricas. Colmo 2-7 $\times 0,2 \mathrm{~cm}$, cilíndrico. Folhas 6-12, ao longo do caule, $0,7-2 \times 0,2-0,25 \mathrm{~cm}$, subcilíndricas, canaliculadas, arqueadas, ápice agudo, crassas. Inflorescência terminal, racemo, pauciflora, laxa; 
séssil; raque $0,15 \mathrm{~cm}$ compr.; brácteas florais 0,05 cm compr. Flores ressupinadas, róseas; sépala dorsal $0,11-0,13 \times 0,08-0,1 \mathrm{~cm}$, oblonga, ápice agudo; sépalas laterais $0,15-0,17 \times 0,1 \mathrm{~cm}$, oblongas, ápice agudo; pétalas $0,15-0,2 \times 0,07-0,08 \mathrm{~cm}$, elípticas, ápice agudo; labelo $0,15-0,2 \times 0,1 \mathrm{~cm}$, ovado, ápice arredondado; coluna 0,07-0,1 cm compr., parcialmente adnata ao labelo; ovário pedicelado $0,15 \mathrm{~cm}$ compr. Fruto $0,4 \times 0,1 \mathrm{~cm}$, fusiforme.

Material examinado selecionado: Mata de Piedade, 23.XI.2009, fl. e fr., E. Pessoa \& J.A.N. Souza 115 (UFP); 16.XII.2009, fl. e fr., E. Pessoa \& J.A.N. Souza 203 (HST, IPA, UFP).

Distribuída desde o México até a América do Sul (Romero-González 2003). Ocasional em tabuleiros e sítios ripários. Ocorre preferencialmente no sub-bosque. Seu pequeno porte e as folhas subcilíndricas arqueadas a diferencia das demais espécies da área.

10. Notylia Lindl.

10.1 Notylia cf. barkeri Lindl., Edwards's Bot. Reg. 24: 90. 1838.

Epífita, simpodial. Raízes cilíndricas. Pseudobulbo 1.1-2 × 0,4-0,6 cm, heteroblástico, achatados lateralmente. Folhas 1-2 basais, 1 apical, 2,5-16,5 × 1-4,7 cm, oblongas à oblongoelípticas, ápice obtuso a arredondado, coriáceas. Inflorescência lateral, racemo, multiflora, congesta, pêndula; pedúnculo 5-13 cm compr.; raque 5-23 cm compr.; brácteas florais $0,1-0,4 \mathrm{~cm}$ compr. Flores não observadas. Fruto não observado.

Material examinado: Mata de Piedade, 25.XI.2009, E. Pessoa \& J.A.N. Souza 196(UFP); 4.III.2010, E. Pessoa \& J.D. Garcia 298 (UFP).

Ocorre no Norte e Nordeste do Brasil (Barros \& Félix 2006; Silva et al. 1995). Na área foi observada uma grande variação no tamanho dos indivíduos, podendo inclusive diferenciar dois possíveis morfotipos. Porém, em função da limitada disponibilidade de estudos para o gênero, acervo escasso nos herbários regionais e as amostras não apresentarem flores optou-se pelo uso de apenas um epíteto que englobe a variabilidade morfológica encontrada na área. Rara em tabuleiros. Pode ser diferenciada das demais espécies da área por possuir inflorescências pêndulas.

11. Oeceoclades Lindl.

11.1 Oeceoclades maculata (Lindl.) Lindl., Gen. Sp. Orchid. Pl. 237-238. 1863.

Fig. 1o

Terrestre, simpodial. Raízes cilíndricas. Pseudobulbo 1,5-3,3 ×0,8 cm, heteroblástico, ovóide. Folhas 1, apical, 16,5-33,5 × 2,7-3,7 cm, elíptica, ápice agudo, coriácea. Inflorescência lateral, racemo, pauciflora, laxa; pedúnculo 22-34 cm compr.; raque 5-14,5 cm compr.; brácteas florais 0,8-1 cm compr. Flores ressupinadas, marrons; sépala dorsal $0,9-1 \times 0,2 \mathrm{~cm}$, oblanceolada, ápice agudo; sépalas laterais $0,8-0,9 \times 0,15-0,25 \mathrm{~cm}$, sub-falcadas, ápice agudo; pétalas $0,7-0,8 \times$ $0,25 \mathrm{~cm}$, elípticas, ápice agudo; labelo $0,8 \times 0,7$ $\mathrm{cm}$, trilobado, ápice bilobado; calcar 0,3-0,4 cm compr., escrotiforme; coluna 0,3-0,4 cm compr.; ovário pedicelado $1-1,1 \mathrm{~cm}$ compr. Fruto 3-3,7 $\times 0,8-1 \mathrm{~cm}$, elipsóide.

Material examinado selecionado: Mata de Piedade, 16.IX.2009, fr. T.A. Pontes \& J.D. Garcia 216 (HST, IPA, UFP); 9.III.2010, fl., E. Pessoa \& J.D. García 309 (IPA); Santa Helena: 28/I/2009, fl. e fr., E. Pessoa \& T. A. Pontes 40 (HST); Zambana: 22.XII.2007, fr. A. AlvesAraújo et al. 763 (UFP).

Amplamente distribuída, desde o estado americano da Florida à América do Sul, além da África tropical (Romero-González 2003). Comum em tabuleiros, declives, terraços e sítios ripários. Parece estar relacionada com áreas parcialmente antropizadas. Diferencia-se das demais espécies da área por possuir pseudobulbos unifoliados e flores com calcar escrotiforme.

12. Polystachya Hook.

12.1 Polystachya concreta (Jacq.) Garay \& H.R. Sweet, Fl. Lesser Antilles 1: 178. 1974. Fig. 2a Epífita, simpodial. Raízes cilíndricas. Pseudobulbo 0,7-2 × 0,3-0,6 cm, homoblástico, ovóide. Folhas 2-4, ao longo do caule, 6-16 × 0,8-2,2 $\mathrm{cm}$, elípticas, ápice obtuso, coriáceas. Inflorescência terminal, racemo ou panícula, multiflora, subcongesta; pedúnculo 4-13,5 cm compr.; raque 2-10 cm compr.; brácteas florais $0,1-0,2 \mathrm{~cm}$ compr. Flores não ressupinadas, alvo-esverdeadas; sépala dorsal 0,25-0,3 × 0,1-0,12 cm, lanceolada, ápice agudo; sépalas laterais $0,3-0,45 \times 0,23-0,32 \mathrm{~cm}$, deltóides, ápice agudo; pétalas $0,22-0,3 \times 0,03-0,06 \mathrm{~cm}$, estreito-oblanceoladas, ápice agudo; labelo 0,4 $\times 0,3$ $\mathrm{cm}$, trilobado, ápice arredondado; coluna $0,1-0,2 \mathrm{~cm}$ compr.; ovário pedicelado $0,15-0,4 \mathrm{~cm}$ compr. Fruto $1-1,2 \times 0,2 \mathrm{~cm}$, fusiforme.

Material examinado: Mata dos Macacos: 19.XII.2007, fl. e fr., D. Araújo \& A. Alves-Araújo 508 (UFP); Mata de Piedade, 25.XI.2009, fr., E. Pessoa \& J.A.N. Souza 195 (UFP).

Espécie com distribuição pantropical (RomeroGonzález 2003). Rara em tabuleiros, onde ocorrem áreas ensolaradas, como clareiras ou bordas. Pode 

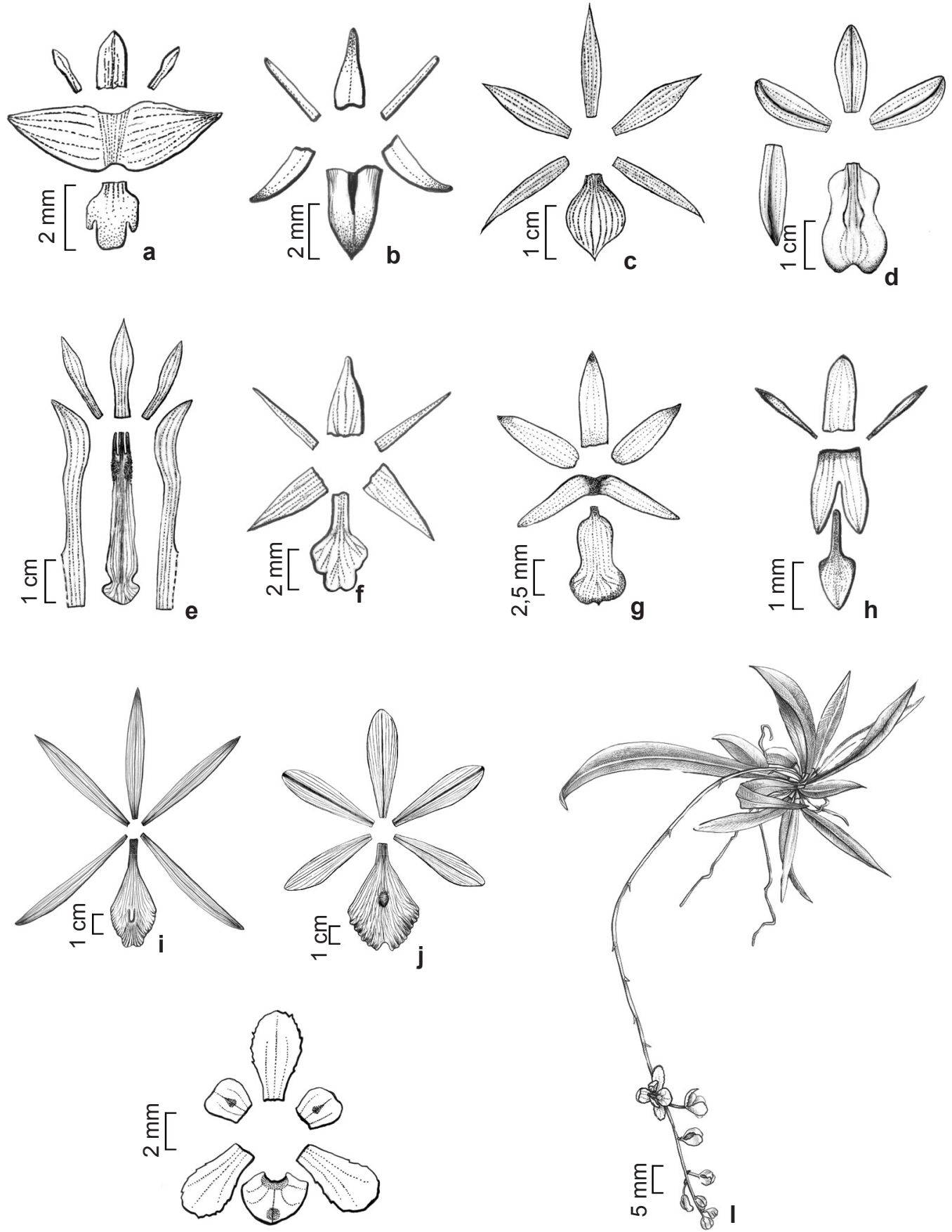

Pollyanna Queiroz

k
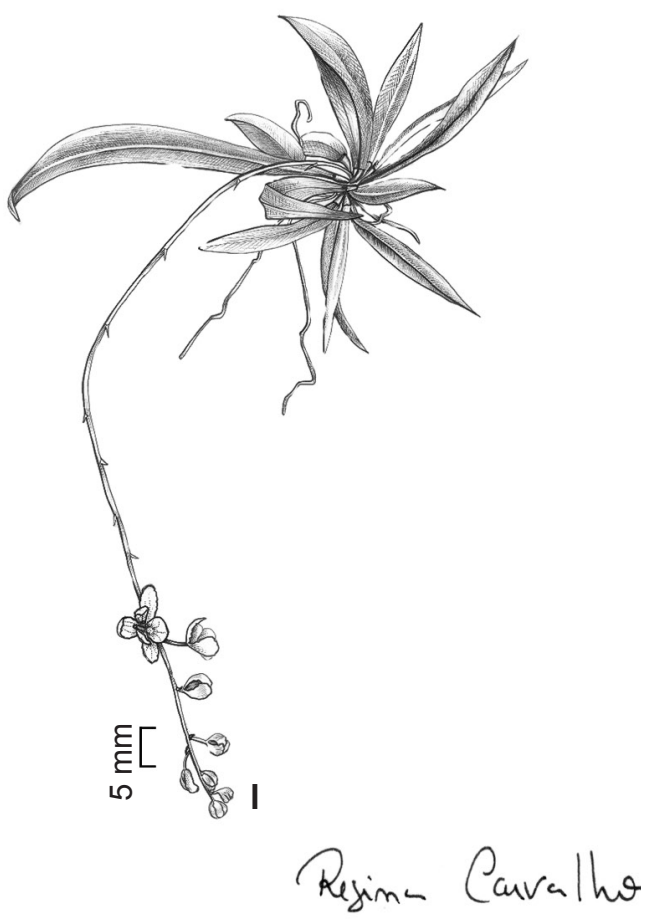

Figura 2 - Diagramas florais. a. Polystachya concreta; b. Prescottia stachyodes; c. Prosthechea fragrans (Sw.); d. Rodriguezia bahiensis f.; e. Sarcoglottis grandiflora; f. Scaphyglottis emarginata; g. Scaphyglottis fusiformis; h. Scaphyglottis sickii; i. Vanilla bahiana; j. Vanilla planifolia; k-1. Zygostates bradei.

Figure 2 - Floral Diagrams. a. Polystachya concreta; b. Prescottia stachyodes; c. Prosthechea fragrans; d. Rodriguezia bahiensis f.; e. Sarcoglottis grandiflora; f. Scaphyglottis emarginata; g. Scaphyglottis fusiformis; h. Scaphyglottis sickii; i. Vanilla bahiana; j. Vanilla planifolia Andrews; k-1. Zygostates bradei. 
ser diferenciada das demais espécies da área por possuir flores diminutas, alvo-esverdeadas e não ressupinadas.

\section{Prescottia Lindl.}

13.1 Prescottia stachyodes (Sw.) Lindl., Edward's Bot. Reg. 22: t. 1915. 1836.

Fig. 2b, $3 g$

Terrestre, simpodial. Raízes cilíndricas. Colmo 3,5-6 $\times 0,4-0,5 \mathrm{~cm}$, cilíndrico. Folhas 2-4, ao longo do caule, 28-32 × 2,7-3,5 cm, elípticas, ápice agudo, membranáceas. Inflorescência terminal, racemo, multiflora, congesta; pedúnculo 30-37 cm compr.; raque 8,5-22 cm compr.; brácteas florais $0,8 \mathrm{~cm}$ compr. Flores não ressupinadas, creme-esverdeadas; sépala dorsal 0,25-0,3 ×0,1 cm, lanceolada, ápice agudo; sépalas laterais $0,25-0,32 \times 0,1 \mathrm{~cm}$, lanceoladas, ápice agudo; pétalas $0,22-0,3 \times 0,05 \mathrm{~cm}$, lineares, ápice agudo; labelo 0,3-0,32 ×0,2-0,25 cm, cuculado, ápice agudo; coluna 0,15-0,2 cm compr.; ovário pedicelado 0,3-0,4 cm compr. Fruto não observado.

Material examinado: Mata dos Macacos: 16.VIII.2007, fl. e fr., A. Alves-Araújo et al. 533 (UFP); Mata de Piedade, 13.VI.2009, T.A. Pontes 209 (UFP).

Ocorre desde o sul do México até o norte da Argentina (Romero-González 2003). Rara em tabuleiros. Observada em áreas sombreadas na floresta. Pode ser diferenciada das demais espécies da área pelas flores não ressupinadas com labelo cuculado.

\section{Prosthechea Knowles \& Westc}

14.1 Prosthechea fragrans (Sw.) W.E. Higgins, Phytologia 82(5): 377. 1997[1998].

Fig. 2c

Epífita, simpodial. Raízes cilíndricas. Pseudobulbo 5,5-6,5 × 0,4-0,8 cm, heteroblástico, claviforme. Folhas 1-2, apicais, 7,5-20 × 1,2-2,2 $\mathrm{cm}$, estreito-elípticas, ápice agudo, coriáceas. Inflorescência terminal, racemo, pauciflora, laxa; pedúnculo 3,3-4,5 cm compr.; raque 1,8-2,7 cm compr.; brácteas florais $0,3 \mathrm{~cm}$ compr. Flores não ressupinadas, alvas; sépala dorsal $2 \times 0,3 \mathrm{~cm}$, estreito-elíptica, ápice agudo; sépalas laterais $1,7-1,8 \times 0,2-0,3 \mathrm{~cm}$, estreito-elípticas, ápice agudo; pétalas $1,7-1,8 \times 0,5 \mathrm{~cm}$, oblanceoladas, ápice agudo; labelo $1,4 \times 0,9 \mathrm{~cm}$, orbicular, ápice acuminado; coluna $0,7 \mathrm{~cm}$ compr., parcialmente fundida ao labelo; ovário pedicelado $1,3 \mathrm{~cm}$ compr. Fruto 2,5-3 × 2-2,5 cm, globoso-elípsóide.

Material examinado: Mata de Piedade, 16.XII.2009, E. Pessoa 207 (HST, IPA, UFP).

Material adicional: BRASIL, Pernambuco: Ipojuca, 31.VIII.2008, fl. e fr., J.B. Oliveira \& A.M. Wanderley s/n (UFP 58424).
Amplamente distribuída nas regiões tropicais da América do Sul, Central e Antilhas (Pabst \& Dungs 1975). Ocasional em tabuleiros, sendo encontrada no dossel e no sub-bosque. É facilmente diferenciada das demais espécies da área por possuir pseudobulbos 1-2 foliados e inflorescências terminais com flores não ressupinadas.

\section{Rodriguezia Ruiz \& Pav.}

15.1 Rodriguezia bahiensis Rchb. f., Bonplandia (Corrientes) 2: 90. 1854.

Fig. 2d

Epífita, simpodial. Raízes cilíndricas. Pseudobulbo 3,5-4 × 0,9-1,1 cm, heteroblástico, ovóide a claviforme. Folhas 2 basais, 1 apical, $7,5-27 \times 1,8-2 \mathrm{~cm}$, estreito-elípticas, ápice emarginado a assimétrico, coriáceas. Inflorescência lateral, racemo, multiflora, laxa; pedúnculo 10-13 cm compr.; raque 3,2-9 cm compr.; brácteas florais 0,4-0,6 cm compr. Flores ressupinadas, alvas; sépala dorsal 1,6-1,7 × 0,5-0,6 cm, elíptica, ápice agudo; sépalas laterais 1,8-2 $\times 0,3-0,4 \mathrm{~cm}$, oblanceoladas, ápice agudo, completamente conadas; pétalas 1,5-1,7 × 0,5-0,6 $\mathrm{cm}$, elípticas, ápice agudo; labelo 2-2,1 × 1-1,1 cm, oblanceolado, ápice emarginado; coluna $0,8-1 \mathrm{~cm}$ compr.; ovário pedicelado $0,9-1,2 \mathrm{~cm}$ compr. Fruto 3,5-4,3 × 1-1,3 cm, globoso-elipsóide.

Material examinado selecionado: Mata do Pezinho: 19.III.2009, fr. L.M. Nascimento \& G. Batista 809 (UFP); Mata de Piedade, 7.III.2009, fl. E. Pessoa et al. 65 (UFP).

Distribui-se no Nordeste e Sudeste brasileiro (Pabst \& Dungs 1977). Comum em tabuleiros, com ocorrência em áreas de borda e no sub-bosque. Pode ser facilmente diferenciada das demais espécies da área por possuir flores alvas com sépalas laterais completamente conadas.

\section{Sarcoglottis C. Presl.}

16.1 Sarcoglottis grandiflora (Lindl.) Klotzsch., Allg. Gartenz. 10: 107. 1842. Fig. 2e, 3h

Terrestre, simpodial. Raízes cilíndricas. Caule reduzido. Folhas 4-5, em roseta basal, 13-27 × 5,5-22 cm, oblanceoladas, ápice agudo, membranáceas. Inflorescência terminal, racemo, pauciflora, laxa; pedúnculo 25-33 cm compr.; raque 3,5-12,5 cm compr.; brácteas florais 3,2-3,5 cm compr. Flores ressupinadas, alvo-esverdeadas; sépala dorsal $2,2 \times 0,35 \mathrm{~cm}$, lanceolada, ápice agudo; sépalas laterais 4,5 × 0,5-0,55 cm, oblanceoladas, ápice agudo, fundidas na base; pétalas $1,6-1,8 \times 0,25-0,3 \mathrm{~cm}$, oblanceoladas, ápice agudo; labelo $3,5 \times 0,8 \mathrm{~cm}$, ligulado, 

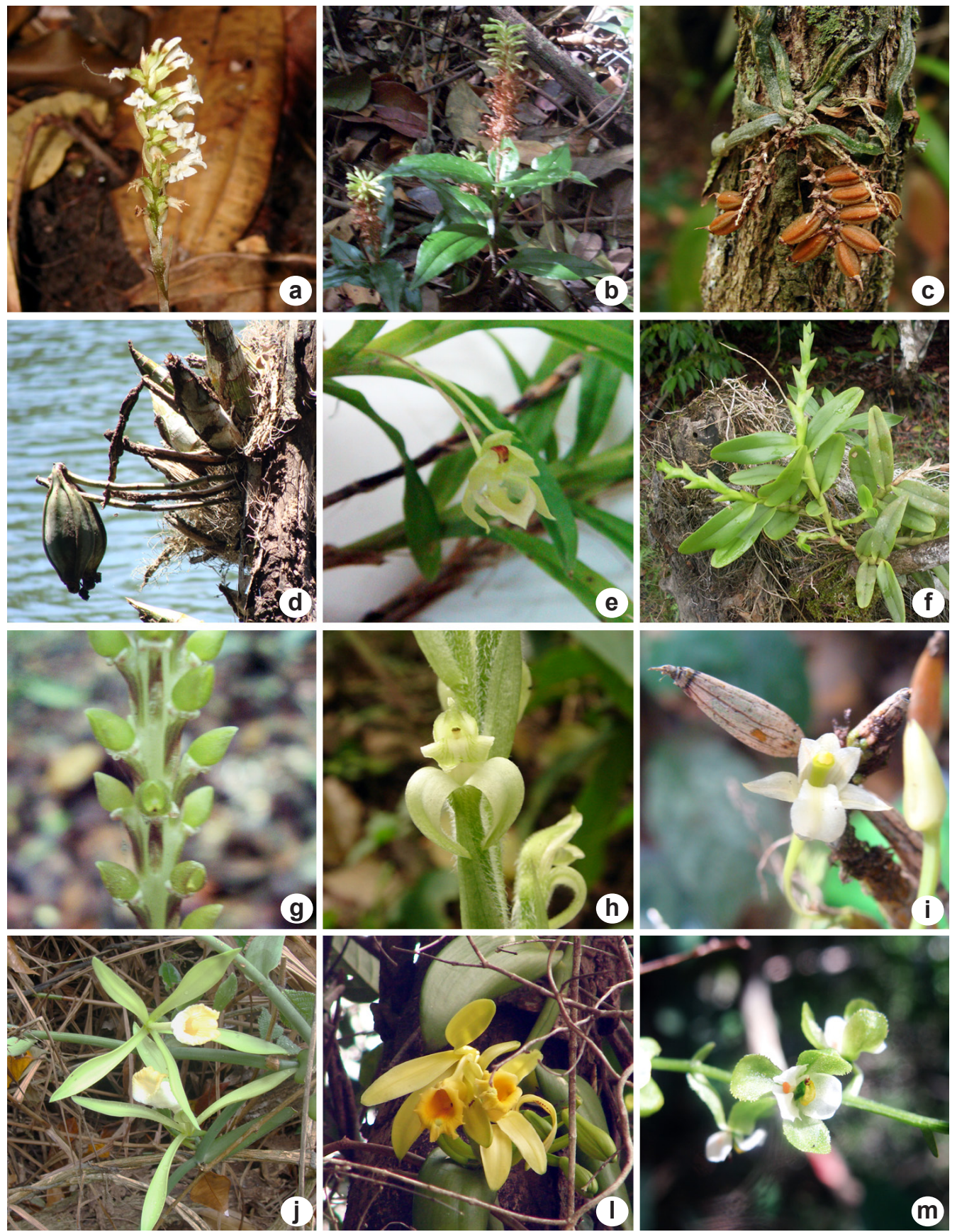

Figura 3 - a. Aspidogyne fissirostris - inflorescência; b. Aspidogyne foliosa - hábito; c. Campylocentrum pachyrrhizum - hábito; d. Catasetum macrocarpum - hábito com frutos; e. Dichaea panamensis - flor; f. Epidendrum rigidum hábito; g. Prescottia stachyodes - flor; h. Sarcoglottis grandiflora - flor; i. Scaphyglottis fusiformis - flor; j. Vanilla bahiana - flor; 1. Vanilla planifolia - flor; m. Zygostates bradei - flor.

Figure 3 - a. Aspidogyne fissirostris - inflorescence; b. Aspidogyne foliosa - habit; c. Campylocentrum pachyrrhizum - habit; d. Catasetum macrocarpum - habit with fruits; e. Dichaea panamensis - flower; f. Epidendrum rigidum - habit; g. Prescottia stachyodes - flower; h. Sarcoglottis grandiflora - flower; i. Scaphyglottis fusiformis - flower; J. Vanilla bahiana - flower; 1. Vanilla planifolia - flower; $\mathrm{m}$. Zygostates bradei - flower. 
constricto no terço distal, ápice arredondado; coluna 1,3 cm compr.; ovário pedicelado 3-3,5 cm compr. Fruto não observado.

Material examinado selecionado: Mata dos Macacos: 15.VIII.2007, fl., A. Alves-Araújo 518 (UFP); Mata de Piedade, 16.IX.2009, fl., T.A. Pontes 217 (IPA, UFP);16. IX.2009, fl., J.D. García \& K. Rajput 1200 (UFP), 10.IX.2008, fl., A. Alves-Araújo 1056 (UFP).

Ocorre no Norte e Nordeste do Brasil (Barros \& Félix 2006; Ilkiu-Borges \& Cardoso 1996). Comum em tabuleiros, declives e terraços. Prefere lugares sombreados na floresta. Pode ser facilmente diferenciada entre as espécies da área por possuir flores rígidas, cuja sépala dorsal é côncava e encurvada, e as laterais reflexas, expondo o labelo.

17. Scaphyglottis Poepp. \& Endl.

17.1 Scaphyglottis emarginata (Garay) Dressler, Brittonia 56(1): 64. 2004. Fig. $2 \mathrm{f}$

Epífita, simpodial. Raízes cilíndricas. Pseudobulbos 5-12 × 0,2-0,3 cm, heteroblásticos, cilíndricos, sobrepostos. Folhas 1, apical, 9-24,5 $\times 0,2 \mathrm{~cm}$, cilíndrica, ápice agudo. Inflorescência terminal, racemo, pauciflora, laxa; séssil; raque 0,2-0,3 cm compr.; brácteas florais 1,1-1,2 cm compr. Flores ressupinadas, alvas; sépala dorsal $0,4-0,45 \times 0,15-0,2 \mathrm{~cm}$, lanceolada, ápice acuminado; sépalas laterais $0,4-0,5 \times 0,1-0,2 \mathrm{~cm}$, lanceoladas, ápice acuminado; pétalas 0,4-0,45 $\times$ $0,05 \mathrm{~cm}$, lineares, ápice agudo; labelo $0,55-0,6 \times$ $0,2 \mathrm{~cm}$, oblanceolado, ápice emarginado; coluna $0,3-0,35 \mathrm{~cm}$ compr.; ovário pedicelado $0,8 \mathrm{~cm}$ compr. Fruto $1,1-1,6 \times 0,3 \mathrm{~cm}$, fusiforme.

Material examinado selecionado: Mata de Piedade, 16.XII.2009, fl. e fr., E. Pessoa \& J.A.N. Souza 200 (HST, IPA, JPB, MAC, UFP).

Ocorre no Norte e Nordeste do Brasil (Barros \& Félix 2006; Ilkiu-Borges \& Cardoso 1996). Rara em tabuleiros, onde ocorre em árvores de grande porte. Os pseudobulbos sobrepostos somados as suas folhas cilíndricas a tornam facilmente identificável.

17.2 Scaphyglottis fusiformis (Griseb.) R. E. Schult., Bot. Mus. Leafl. 17(7): 205. 1956.

Fig. $2 \mathrm{~g}, 3 \mathrm{i}$

Epífita, simpodial. Raízes cilíndricas. Pseudobulbo 2,5-8 × 0,2-0,55 cm, heteroblástico, fusiformes, sobrepostos. Folhas 1, apical, 2-7,5 $\times$ 0,3-0,4 cm, linear, ápice emarginado, coriácea. Inflorescência terminal, racemo, pauciflora, laxa; pedúnculo $1-1,2 \mathrm{~cm}$ compr.; raque $0,4-0,45 \mathrm{~cm}$ compr.; brácteas florais $0,3-0,35 \mathrm{~cm}$ compr. Flores ressupinadas, alvas; sépala dorsal $0,6 \times 0,15-0,25$ $\mathrm{cm}$, lanceolada, ápice agudo; sépalas laterais $0,65-0,75 \times 0,15-0,3 \mathrm{~cm}$, lanceoladas, ápice agudo; pétalas $0,6 \times 0,2 \mathrm{~cm}$, elípticas, ápice agudo; labelo $0,65-0,8 \times 0,4 \mathrm{~cm}$, obovado, ápice cuspidado; coluna $0,42-0,5 \mathrm{~cm}$ compr.; ovário pedicelado $1,2-2 \mathrm{~cm}$ compr. Fruto $1,9-2,3 \times 0,15-0,25 \mathrm{~cm}$, fusiforme.

Material examinado: Mata de Piedade, 16.XII.2009, fl. e fr., E. Pessoa \& J.A.N. Souza 204 (HST, IPA, UFP, $\mathrm{MAC}$ ).

Ocorre desde o Panamá ao Brasil (RomeroGonzález 2003). Ocasional em tabuleiros. Com ocorrência preferencial no sub-bosque. Pode ser confundida na área com S. sickii Pabst, mas pode ser diferenciadamas diferencia-se pelos pseudobulbos unifoliolados.

\subsection{Scaphyglottis sickii Pabst, Orquídea (Niteroi)} 18: 7. 1956. Fig. $2 \mathrm{~h}$

Epífita, simpodial. Raízes cilíndricas. Pseudobulbo 2,5-8 × 0,2-0,25 cm, heteroblástico, cilíndrico, sobrepostos. Folhas 2, apicais, 2-,3 3 $0,3-0,6 \mathrm{~cm}$, lineares, ápice emarginado, coriáceas. Inflorescência terminal, racemo, pauciflora, congesta; séssil; raque $0,1-0,15 \mathrm{~cm}$ compr.; brácteas florais $0,3-0,4 \mathrm{~cm}$ compr. Flores ressupinadas, alvas; sépala dorsal $0,2-0,25 \times 0,05-0,09 \mathrm{~cm}$, oblanceolada, ápice agudo; sépalas laterais 0,2 $0,25 \times 0,05-0,07 \mathrm{~cm}$, oblanceoladas, ápice agudo, conadas no terço inferior; pétalas $0,2-0,3 \times 0,01$ $\mathrm{cm}$, lineares, ápice agudo; labelo $0,2-0,3 \times 0,1 \mathrm{~cm}$, elíptico, ápice agudo; coluna $0,25-0,3 \mathrm{~cm}$ compr.; ovário pedicelado $0,25 \mathrm{~cm}$ compr. Fruto $0,4-0,5 \times$ $0,2-0,25 \mathrm{~cm}$, elipsoide.

Material examinado selecionado: Mata de Piedade, 25.XI.2009, fl. e fr., E. Pessoa \& J.A.N. Souza 191 (IPA, UFP); 16.XII.2009, fl. e fr., E. Pessoa \& J.A.N. Souza 202 (HST, UFP).

Ocorre desde a Costa Rica ao Brasil (RomeroGonzález 2003). Ocasional em tabuleiros e terraços, com preferência pelo sub-bosque. Pode ser confundida na área com $S$. fusiformis, podendo ser diferenciada por possuir duas folhas apicais.

\section{Vanilla Mill.}

18.1 Vanilla bahiana Hoehne, Arq. Bot. Estado São Paulo 2(5): 108. 1950. Fig. $2 \mathrm{i}, 3 \mathrm{j}$

Hemiepífita. Raízes cilíndricas. Colmo volúvel, entrenós 9,5-15,5×0,4 cm larg., cilíndrico. Folhas ao longo do caule, 4,7-11,5 × 1,5-1,8 cm, estreito-elípticas, ápice agudo, crassas. Inflorescência lateral, racemo, pauci a multiflora, sub-congesta; 
pedúnculo $0,2-0,6 \mathrm{~cm}$ compr.; raque $2,8-5,6 \mathrm{~cm}$ compr.; brácteas florais $0,4-0,75 \mathrm{~cm}$ compr. Flores ressupinadas, alvo-esverdeadas; sépala dorsal 2,27,8 $\times 0,6-1 \mathrm{~cm}$, oblanceolada, ápice agudo; sépalas laterais 2,2-7,8 $\times 0,6-1 \mathrm{~cm}$, oblanceoladas, ápice agudo; pétalas 2,2-7,8 × 0,6-1 cm, oblanceoladas, ápice agudo; labelo 2,2-6 × 1,5-2,4 cm, obovado, ápice cuspidado, fundido lateralmente com a coluna; coluna 1,7-3 cm compr.; ovário pedicelado $3-4 \mathrm{~cm}$ compr. Fruto $8 \times 1,5 \mathrm{~cm}$, fusiforme.

Material examinado: Mata de Chave: 24.XI.2009, fl. e fr., E. Pessoa \& J.A.N. Souza 150 (EAN, HST, IPA, JPB, MAC, UFP); Zambana: 21.III.2007, fl., D. Araújo et al. 186 (UFP).

Restrita ao Nordeste, Sudeste e CentroOeste do Brasil (Félix \& Carvalho 2002; Fraga \& Peixoto 2004; Batista \& Bianchetti 2003). Comum na borda, tabuleiro, declive e terraço. Apesar de comum na área, indivíduos floridos são encontrados apenas no dossel, ou mais raramente na borda. Diferencia-se mais facilmente da outra espécie da área pelas flores alvo-esverdeadas.

18.2 Vanilla planifolia Andrews, Bot. Repos. 8: t. 538. 1808. Fig. 2 j, 31

Hemiepífita. Raízes cilíndricas. Colmo volúvel, entrenós 9,5-10,5 × 0,6-0,7 cm larg., cilíndrico. Folhas, ao longo do caule, 16,5-19 × 3,8-5 cm, oblongas, ápice agudo, crassas. Inflorescência lateral, racemo, pauci a multiflora, sub-congesta; pedúnculo $0,5 \mathrm{~cm}$ compr.; raque $4 \mathrm{~cm}$ compr.; brácteas florais $0,7-1 \mathrm{~cm}$ compr. Flores ressupinadas, amarelas; sépala dorsal 5,1 × 1,3 cm, oblanceolada, ápice obtuso; sépalas laterais 4,8-5 × 1-1,2 cm, oblanceoladas, ápice obtuso; pétalas 4,8 $\times 1,2-1,3 \mathrm{~cm}$, oblanceoladas, ápice obtuso; labelo 4,5-5,5 × 2,4-2,6 $\mathrm{cm}$, obovado, ápice bilobado, fundido lateralmente com a coluna; coluna 2,1-2,3 cm compr.; ovário pedicelado 4-4,5 cm compr. Fruto não observado.

Material examinado: Mata de Piedade, 09.XII.2008, fl., E. Pessoa et al. 22 (UFP).

Ocorre do México ao sul do Brasil (RomeroGonzález 2003). Ocasional em borda e tabuleiros. Observada em floração apenas nas áreas com iluminação direta. Pode ser diferenciada da outra espécie do gênero na área pelas flores amarelas.

19. Zygostates Lindl.

19.1 Zygostates bradei (Schltr.) Garay, Bot. Mus. Leafl. 21: 263. 1967.

Fig. 2k-1, 3m

Epífita, simpodial. Raízes cilíndricas. Pseudobulbo $0,3-0,6 \times 0,25-0,4 \mathrm{~cm}$, heteroblástico, ovóide. Folhas 3 basais, 1 apical, 2,6-7 × 0,3-0,6 $\mathrm{cm}$, estreito-elípticas, ápice agudo, coriáceas. Inflorescência lateral, racemo, raro ramificada, multiflora, laxa; pedúnculo 6-11,5 cm compr.; raque $2-9 \mathrm{~cm}$ compr.; brácteas florais $0,1-0,2 \mathrm{~cm}$ compr. Flores, ressupinadas, alvo-esverdeadas; sépala dorsal $0,55-0,6 \times 0,25-0,3 \mathrm{~cm}$, espatulada, ápice truncado a arredondado; sépalas laterais $0,55-0,6 \times 0,25-0,3 \mathrm{~cm}$, livres, espatuladas, ápice truncado a arredondado; pétalas $0,2-0,3 \times 0,2 \mathrm{~cm}$, suborbiculares a espatuladas, ápice truncado a arredondado; labelo $0,3 \times 0,4 \mathrm{~cm}$, orbicular, ápice arredondado; coluna $0,2-0,3 \mathrm{~cm}$ compr.; ovário pedicelado $0,4-0,5 \mathrm{~cm}$ compr. Fruto $1,1-1,2 \times$ 0,3-0,4 cm, globoso.

Material examinado selecionado: Mata de Piedade, 16.XII.2009, fl. e fr., E. Pessoa \& J.A.N. Souza 210 (HST, IPA, UFP); 9.III.2010, fl. e fr., E. Pessoa \& J.D. García 312 (MAC, UFP).

Distribuída no Nordeste e Sudeste do Brasil (Felix \& Carvalho 2002; Schlechter \& Hoehne 1922) e citada entre as espécies ameaçadas de extinção da Fundação Biodiversitas (2008). Ocasional em tabuleiros e sítios ripários, ocorrendo preferencialmente no sub-bosque. Diferencia-se facilmenteda das demais espécies da área por possuir pseudobulbos pequenos (até $0,6 \mathrm{~cm}$ compr.) e folhas estreito-elípticas.

\section{Agradecimentos}

À Usina São José pelo apoio logístico para as coletas, ao CNPq pela bolsa concedida, ao BMBF pelo financiamento do Projeto Fragmentos e aos colegas de laboratório pelo auxílio no desenvolvimento desse trabalho.

\section{Referências}

Almeida, A.; Felix, W.; Andrade, L. \& Felix, L.P. 2007. A família Orchidaceae em inselbergues da Paraíba, Nordeste do Brasil. Revista Brasileira de Biociências 5: 753-755.

Alves-Araújo, A.; Araújo, D.; Marques, J.; Melo, A.; Maciel, J.R.; Irapuan, J.; Pontes, T.; Lucena, M.F.A.; Bocage, A.L. \& Alves, M. 2008. Diversity of angiosperms in fragments of Atlantic Forest in the State of Pernambuco, Northeastern Brazil. Bioremediation, Biodiversity and Bioavailability 2: 14-26.

Alves-Araújo, A. \& Alves, M. 2010. Flora da Usina São José, Igarassu, Pernambuco: Sapotaceae. Rodriguésia 61: 303-318.

Amorim, B.S. \& Alves, M. 2011. Flora da Usina São José, Igarassu, Pernambuco: Myrtaceae. Rodriguésia 62: 499-514. 
Araújo, D. \& Alves, M. 2010. Climbing plants of a fragmented area of lowland Atlantic Forest, Igarassu, Pernambuco (northeastern Brazil). Phytotaxa 8: 1-24.

Azevedo, C. \& Van-Den-Berg, C. 2007. A família Orchidaceae do Parque Municipal de Mucugê, Bahia, Brasil. Hoehnea 34: 1-47.

Barros, F. \& Félix, L.P. 2006. Orchidaceae. In: Barbosa, M.R.V.; Sothers, C.; Mayo, S.; Gamarra-rojas, C.F.L.; Mesquita, A.C. (orgs.). Checklist das Plantas do Nordeste Brasileiro: Angiospermas e Gimnospermas. Ministério de Ciências e Tecnologia, Brasília. Pp. 115-122.

Barros, F.; Vinhos, F.; Rodrigues, V.T.; Barberena, F.F.V.A.; Fraga, C.N. \& Pessoa, E.M. 2012. Orchidaceae. In: Forzza, R.C. et al. (eds.). Lista de Espécies da Flora do Brasil. Jardim Botânico do Rio de Janeiro. Disponível em <http:// floradobrasil.jbrj.gov.br/2012/FB000179>. Acesso em 19 Mar 2012.

Batista, J. \& Bianchetti, L. 2003. Lista atualizada das Orchidaceae do Distrito Federal. Acta Botanica Brasilica 17: 183-201.

Buril, M.T. \& Alves, M. 2011. Flora da Usina São José, Igarassu, Pernambuco: Convolvulaceae. Rodriguésia 62: 93-105.

Chase, M. W.; Williams, N.H.; Faria, A.D.; Neubig, K.M.; Amaral, M.C.E. \& Whitten, W.M. 2009. Floral convergence in Oncidiinae (Cymbidieae; Orchidaceae): an expanded concept of Gomesa and a new genus Nohawilliamsia. Annals of Botany 104: 387-402.

Christenson, E. 2004. Orchidaceae. In: Smith, N.; Mori, S.; Hendersom, A.; Stevenson, D. \& Heald, S. (eds.). Flowering Plants of the Neotropics. New York Botanical Garden, New York. Pp. 465-468.

Conservation International, Fundação SOS Mata Atlântica; Fundação Biodiversitas; Instituto de Pesquisas Ecológicas; Secretaria do Meio Ambiente do Estado de São Paulo \& Instituto de FlorestasMG. 2000. Avaliação e ações prioritárias para a conservação da biodiversidade da Floresta Atlântica e Campos Sulinos. MMA/SBF, Brasília. 41p.

CPRH (Companhia Pernambucana do Meio Ambiente). 2003. Diagnóstico socioambiental do litoral norte de Pernambuco. CPRH, Recife. 214p.

Dressler, R. L. 2003. Orchidaceae. In: Hammel, B.E.; Grayum, M.H. \& Zamora, N. (eds.). Manual de Plantas da Costa Rica. Vol. 3. Monographs in Systematic Botany from the Missouri Botanical Garden 93: 1-595.

Felix, L.P. \& Carvalho, R. 2002. Diversidade de Orquídeas no Estado de Pernambuco. In: Tabarelli, M. \& Silva, J.M.C. (orgs.). Diagnóstico da Biodiversidade de Pernambuco. Vol. 1. Editora Massangana, Recife. Pp. 207-217.
Fraga, C. N. \& Peixoto, A. L. 2004. Florística e ecologia das Orchidaceae das restingas do Espírito Santo. Rodriguésia 55: 5-20.

Fundação Biodiversitas. 2008. Lista da Flora Brasileira Ameaçada de Extinção. Orchidaceae. Disponível em <http://www.biodiversitas.org.br/floraBr/ grupo3fim.asp>. Acesso em 23 Abr 2010.

Gonçalves, E. \& Lorenzi, H. 2007. Morfologia Vegetal - organografia e dicionário Ilustrado de morfologia das plantas vasculares. Instituto Plantarum, São Paulo. 415p.

Harris, J. \& Harris, M. 2001. Plant identification terminology - An Illustrated Glossary. $2^{\mathrm{a}}$ ed. Spring Lake Publishing, Payson. 260p.

Hoehne, F. C. 1949. Iconografia de Orchidáceas do Brasil. Secretaria de Agricultura, Indústria e Comércio, São Paulo. 302p.

Ilkiu-Borges, A.L. \& Cardoso, A.L. 1996. Notas preliminares sobre a flora orquidológica do Estado do Pará, Brasil. Boletim do Museu Paraense Emílio Goeldi, série botânica 12: 183-205.

Lima-Verde, L. 2003. A subtribo Laeliinae Benth. (Orchidaceae) na Serra de Maranguape, Estado do Ceará, Brasil. Dissertação de Mestrado. Universidade Federal de Pernambuco, Recife.

Melo, A.; Alves-Araújo, A \& Alves, M.V. 2010. Burmanniaceae e Gentianaceae da Usina São José, Igarassu, Pernambuco. Rodriguésia 61: 431-440

Mittermeier, R.; Myers, R. \& Mittermeier, C. 1999. Hotspots. CEMEX, Ciudad México. 431p.

Ministério do Meio Ambiente. 2008. Lista Oficial das Espécies da Flora Brasileira Ameaçadas de Extinção. Instrução Normativa MMA n ${ }^{\circ}$ 06/2008. Disponível em $<$ www.ibama.gov.br/sisbio $>$. Acesso em 03 Set 2009).

Mori, S.A.; Mattos-Silva, L.A.; Lisboa, G. \& Coradin, L. 1985. Manual de Manejo do Herbário Fanerogâmico. $2^{\mathrm{a}}$ ed. CEPLAC/CEPEC, Ilhéus, 104p.

Myers, N.; Mittermeier, R.; Mittermeier, C.; Fonseca, G \& Kent, J. 2000. Biodiversity hotspots for conservation priorities. Nature 403: 845-853

Ormerod, P. 2009. Studies of Neotropical Goodyerinae (Orchidaceae) 4. Harvard Papers in Botany 14: 111-128.

Pabst, G.F.J. \& Dungs, F. 1975. Orchidaceae Brasilienses. Vol. 1. Kurt Schmersow, Hildesheim. 408p.

Pabst, G.F.J. \& Dungs, F. 1977. Orchidaceae Brasilienses. Vol. 2. Kurt Schmersow, Hildesheim. 418p.

Peixoto, A.L.; Rosa, M.M.T. \& Silva, I.M. 2002. Caracterização da Mata Atlântica. In: Sylvestre, L.S. \& Rosa, M.M.T. (eds.). Manual metodológico para estudos botânicos na mata Atlântica. EDUR, Seropédica. Pp. 09-23.

Pontes, T.A.; Andrade, M.I. \& Alves, M. 2010. Flora da Usina São José, Igarassu, Pernambuco: Araceae. Rodriguesia 61: 689-704 
Priggeon, A. 1995. The illustrated encyclopaedia of orchids. Portland, Timber Press. 83p.

Rasmussem, F.N. 1985. Orchidaceae. In: Dahlgrem, R.M.T.; Clifford, T. \& Yeo, P.F. (eds.). The families of the monocotyledons. Springer-Verlag, Berlin. Pp. 249-274.

Ribeiro, M. C.; Metzger, J. P.; Martensen, A.C.; Ponzoni, F.J. \& Hirota, M.M. 2009. The Brazilian Atlantic Forest: How much is left, and how is the remaining forest distributed? Implications for conservation. Biological Conservation 142: 1144-1156.

Romero-González, G.A. 2003. Orchidaceae. In: Berry, P.E.; Holst, K. \& Yatskievych, K. (eds.). Flora of the Venezuelan Guayana. Vol.7. Missouri Botanical Garden, St. Louis. Pp. 200-619.

Schlechter, R. \& Hoehne F.C. 1922. Contribuições ao conhecimento das Orchidáceas do Brasil I. Anexos das Memórias do Instituto de Butantan, Secção Botânica. 1: 1-70

Silva, A.G.; Sá-e-Silva, I.M.M.; Rodal, M.J.N. \& Lins-e-Silva, A.C. 2008. Influence of edge and topography on canopy and sub-canopy structure of an Atlantic Forest fragment in Igarassu, Pernambuco State, Brazil. Bioremediation, Biodiversity and Bioavaliability 2: 41-46

Silva, M.F.; Silva, J.B.; Rocha, A.E.; Oliveira, F.P.; Gonçalves, L.S. \& Queiroz, O.H. 1995. Inventário da família Orchidaceae na Amazônia Brasileira P.1. Acta Botanica Brasilica 9: 163-175

Stehmann, J.R.; Forzza, R.C.; Sobral, M. \& Kamino, L.H.Y. 2009. Gimnospermas e angiospermas. In: Stehmann, J.R.; Forzza, R.C.; Salino, A.; Sobral, M.; Costa, D.P. \& Kamino, L.H.Y. (eds). Plantas da Floresta Atlântica. Jardim Botânico do Rio de Janeiro, Rio de Janeiro. Pp. 27-37.

Thiers, B. 2010. [continuously updated]. Index Herbariorum: A global directory of public herbaria and associated staff. New York Botanical Garden's Virtual Herbarium. Disponível em $<$ http://sweetgum.nybg.org/ih/>. Acesso em 14 Jan 2010 .

Toscano-de-Brito, A.L. 1995. Orchidaceae. In: Stannard, B.L. (ed.). Flora do Pico das Almas, Chapada Diamantina Brasil. Royal Botanic Garden, Kew. Pp.725-767

Toscano-de-Brito, A.L. \& Cribb, P. 2005. Orchidaceae da Chapada Diamantina. São Paulo. Nova Fronteira. 399p.

Trindade, M.B.; Lins-e-Silva, A.C.B.; Silva, H.P.; Figueira, S.B. \& Schess1, M. 2008. Fragmentation of the Atlantic Rainforest in the Northern Coastal Region of Pernambuco, Brazil: Recent changes and implications for conservation. Bioremediation, Biodiversity and Bioavailability 2: 5-13.

Lista de Exsicatas

A. Alves-Araújo 520 (7.3); 763 (11.1); 533 (13.1); 518, 1056 (16.1). A. Melo 240 (3.1). D. Araújo 534 (5.1); 545 (6.1); 477 (11.1); 508 (12.1); 186 (18.1). E. Pessoa 260 (1.1); 105 (1.2); 212, 257, 296, 307 (2.1); 209 (2.2); 81, 192, 213 (3.1); 259 (4.1); 114, 198, 258, 308 (5.1); 112, 201 (6.1); 211, 262, 311 (7.2); 109, 111, 205 (7.3); 104, 214 (7.1); 113, 199 (7.4); 206, 256 (8.1); 115, 203, 295 (9.1); 196, 298 (10.1); 40, 229, 309 (11.1); 195 (12.1); 207 (14.1); 65, 261 (15.1); 200 (17.1); 204 (17.2); 191, 202, 310 (17.3); 150 (18.1); 22 (18.2); 210, 263, 294, 312 (19.1). J.A.N. Souza 580 (1,1); 546 (1.2); 581 (2.1). J.A. Siqueira-Filho 1405 (8.1). J.B. Oliveira s.n. UFP 58424 (14.1). J.D. García 1253 (1.2); 1430 (2.2); 1432 (4.1); 1200 (16.1). J.S. Marques 108 (15.1). L.M. Nascimento 809 (15.1). M.S. Silva s.n. UFP 6956 (4.1). T.A. Pontes 216 (10.1); 209 (13.1); 217 (16.1). 